\title{
Planning for Reliable Coal Quality Delivery Considering Geological Variability: A Case Study in Polish Lignite Mining
}

\author{
Wojciech Naworyta, ${ }^{1}$ Szymon Sypniowski, ${ }^{2}$ and Jörg Benndorf ${ }^{3}$ \\ ${ }^{1}$ Department of Surface Mining, AGH University of Science and Technology, Mickiewicza Avenue 30, 30-059 Krakow, Poland \\ ${ }^{2}$ Department of Mineral Resources Acquisition, MEERI PAS, Wybickiego Street 7, 31-261 Krakow, Poland \\ ${ }^{3}$ Faculty of Civil Engineering and Geoscience, Delft University of Technology, Building 23, Stevinweg 1, \\ P.O. Box 5048, 2600 GA Delft, Netherlands
}

Correspondence should be addressed to Wojciech Naworyta; naworyta@agh.edu.pl

Received 20 August 2014; Accepted 9 January 2015

Academic Editor: Michael A. Delichatsios

Copyright (C) 2015 Wojciech Naworyta et al. This is an open access article distributed under the Creative Commons Attribution License, which permits unrestricted use, distribution, and reproduction in any medium, provided the original work is properly cited.

\begin{abstract}
The aim of coal quality control in coal mines is to supply power plants daily with extracted raw material within certain coal quality constraints. On the example of a selected part of a lignite deposit, the problem of quality control for the runof-mine lignite stream is discussed. The main goal is to understand potential fluctuations and deviations from production targets dependent on design options before an investment is done. A single quality parameter of the deposit is selected for this analysis-the calorific value of raw lignite. The approach requires an integrated analysis of deposit inherent variability, the extraction sequence, and the blending option during material transportation. Based on drill-hole data models capturing of spatial variability of the attribute of consideration are generated. An analysis based on two modelling approaches, Kriging and sequential Gaussian simulation, reveals advantages and disadvantages lead to conclusions about their suitability for the control of raw material quality. In a second step, based on a production schedule, the variability of the calorific value in the lignite stream has been analysed. In a third step the effect of different design options, multiple excavators and a blending bed, was investigated.
\end{abstract}

\section{Introduction}

Environmental and economic considerations in the electrical energy industry rise the necessity to constantly improve the efficiency of power units. One way to increase the efficiency of energy production in the power plants based on fossil fuels is to supply the raw material with specific and relatively stable quality parameters.

In the case of lignite, the spatial variability of parameters is quite large. Given the variability criterion, lignite belongs to the second group of deposits in the Polish classification. The coefficient of variation $\mathrm{v}[\%]$ is defined as the ratio of the standard deviation to the mean value of the basic parameters and is usually in the range of $30 \%$ to $60 \%$. The exception is the calorific value which has a relatively low volatility in the range of 9 to $16 \%[1]$.
To meet customer's requirements, the planning and design of a mining operation have to focus on technical and operational measures to reduce the in situ variability of critical coal attributes during mining and material handling. The aim of different design options, such as the use of blending beds or multiple excavators simultaneously, is to transform the in situ variability in the deposit to a level which meets customers' requirements. For investigating the effect of a coal blending beds the theory of variance reduction in bed blending is well established (e.g., [2]). It is based on the variogram transformation of the incoming to the outgoing stream. Several documented applications (e.g., $[3,4])$ use techniques of stochastic simulation based on variograms of critical elements to simulate the variability of incoming material flows and to optimise the transformation process. Considering geologically more complex deposits this 
approach may be too simplified. To investigate the homogenisation effects in a continuous mining system, the deposit characteristics, in particular the local variability has to be linked with the extraction method, the mining sequence, and blending options throughout the operation [5].

In order to maintain stable raw material parameters, certain measures are undertaken referred to as the lignite stream quality management (e.g., [5-9]). This process begins with the exploration and documentation of the deposit and is conducted until the end of the mine's life. Coal quality control can be divided into several stages:

(1) identification of critical parameters and modelling of the deposit:

(i) identification and analysis of critical coal quality parameter,

(ii) spatial modelling of the variability of quality parameters,

(2) mine planning (long-term planning):

(i) determination of the location ultimate pit limit and of the opening box cut,

(ii) design of blending options and facilities, such as stock and blending yards,

(iii) establishment of a long-term mining sequence and advances of the mining faces in time,

(3) exploitation and production control (operational planning):

(i) short-term production scheduling for the extraction equipment,

(ii) prediction and online analysis of the quality of the extracted coal,

(iii) logistics and transportation,

(iv) storage and homogenisation of the raw material.

The analysis presented here relates to the second and third stage of the control process - the design of blending options and operational planning. The following sections will first investigate different geostatistical modelling approaches for their suitability to map realistically spatial variability of lignite attribute considered. In the second part the variability of the extracted material flow is evaluated, including bedblending and multiple excavators, leading to design options for improved coal quality management and a reliable supply of the power plant.

This paper is a continuation of the aspects related to coal quality management in lignite mines discussed by the authors in previous publications. In particular, methods of conditional simulation in geostatistics investigated in $[10,11]$ are applied to full scale reserve modelling of a large lignite field in Poland aiming to understand variability of coal quality attributes at a short-term scale. Using these models the second part focuses on design issues of a stock and blending bed to understand its ability to control short-term variation. Contrary to the work described in $[5,12]$, which focuses on operational optimization of a coal stock and blending bed, here the aim is to understand the effect of the bed size to control coal quality fluctuations of final products to be sold. The combined approach discussed in this paper allows decisions on the optimal stock and blending bed design to be evaluated in the design phase, before short-term operation is actually executed and real fluctuations experienced.

\section{The Objective of This Case Study}

For the process of lignite quality control at the stage of operational planning it is necessary to have sufficient exploration information about the deposit. In the mines this task is accomplished in different ways. One of them is to explore the deposit with drill-holes drilled from the roof of the exposed lignite-the so called operational exploration. The holes in the deposit analysed in this paper were drilled in a dense grid of 50 by 50 meters. Although, in comparison to the geological documentation stage, the operational exploration has a higher information content, the actual parameters of the mined lignite still often differ from values identified during this drilling period.

The main objective of this study is to understand possible deviations with respect to the expected calorific of coal produced based on operational exploration data, that is, to assess to what extent these data provide accurate information for the tasks related to the quality control of the mined mineral. To achieve this goal and test the suitability of different approaches, two methods of geostatistical modelling are compared, ordinary Kriging and conditional simulation (e.g., [1]).

In a second step two different design options are investigated focusing on the effect of variability of run-of-mine lignite, which are as follows:

(i) the availability of a coal stock and blending yard for bed blending: different sizes are investigated,

(ii) the availability of a second excavator and the possibility to blend two lignite streams on the belt conveyor.

For run-of-mine lignite quality control in the context of power plant supply multiple parameters such as calorific value, sulphur content, and silica content have to be taken into account. Without loss of generality, this paper focused on the analysis of the calorific value of the raw lignite $Q_{i}^{r}$.

\section{The Method}

On the basis of the operational exploration within the area limits of six-month progress of extraction, variability models of the calorific value in particular mining blocks were created. This analysis was performed for the part of the deposit where the operational exploration is characterized by high regularity. Figure 1 shows the selected part of the deposit with respect to the entire deposit and the assumed mining progress in relation to all exploratory holes.

On the basis of the calorific value variability models with a given mining direction, the variations of calorific value were calculated for a six-month period. Figure 2 shows a sequence of mining 195 consecutive exploitation blocks. Each mining 


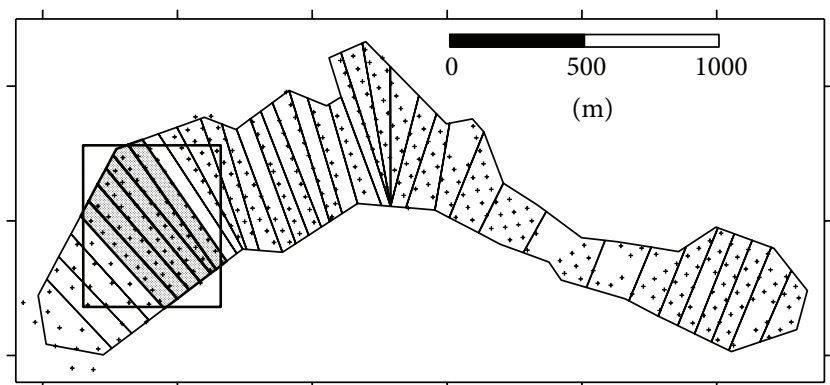

FIGURE 1: Location of the drill holes of the operational exploration and the limits of monthly mining progress. The rectangle marks the area selected for analysis.

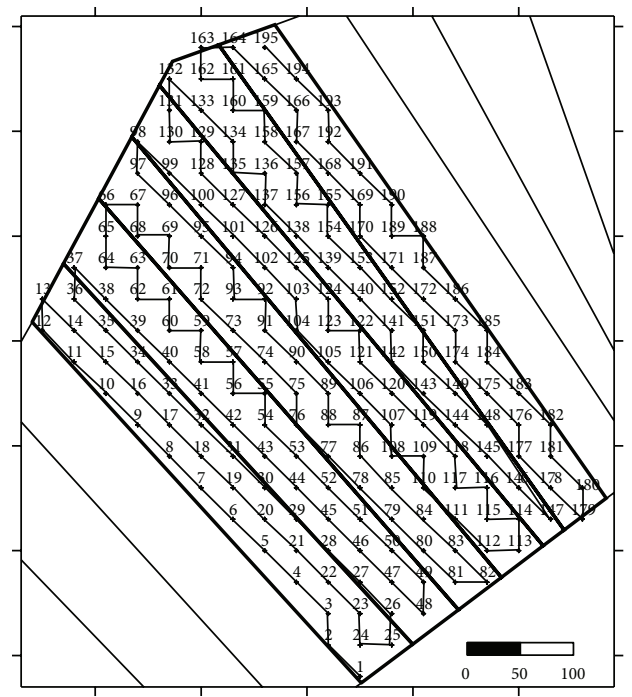

FIGURE 2: The order of exploitation within a six-month period. Each exploitation block has been marked with the number.

block with dimensions of $30 \times 30$ meters corresponds to an actual average daily production of lignite from the analyzed deposit. With the average lignite seam thickness of approximately 6 meters and a density of $1.15 \mathrm{t} / \mathrm{m}^{3}$, a single exploitation block contains about 6,5 thousand tonnes of lignite.

Based on the data the models of spatial variability of the calorific value in the deposit were created using the ordinary Kriging method and the direct sequential simulation method, which are implemented in the software S-GeMS [13]. The geostatistical simulation procedure is based on the idea of MonteCarlo simulation. Based on available observations of the deposit and on random numbers, the simulation can generate any number of models (herein referred to as realizations). The realizations are unique and at the same time characterized by identical probability to represent the actual deposit. All realizations accurately reflect the values at the observation points. Unlike ordinary Kriging, realizations resulting from simulation accurately reflect the statistical and structural features of the modelled parameters such as the density distribution and spatial variability. Local differences between

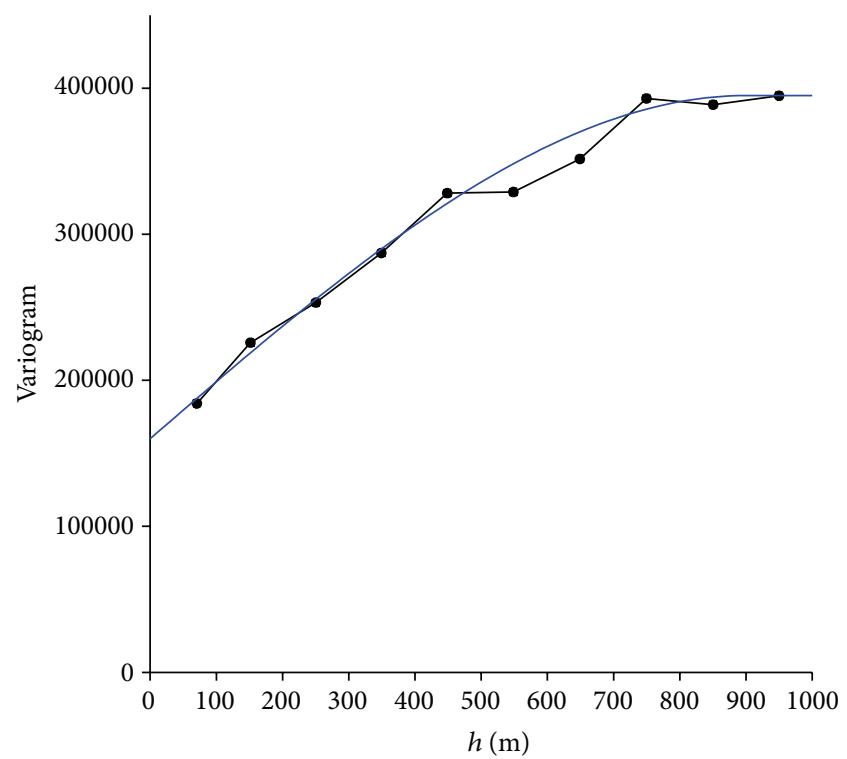

FIGURE 3: Experimental variogram with variogram model.

TABLE 1: Basic features of variogram model of calorific value.

\begin{tabular}{lc}
\hline Variogram model & Dimension and unit \\
\hline Nugget effect & $160000(\mathrm{~kJ} / \mathrm{kg})^{2}$ \\
Spherical model & $235000(\mathrm{~kJ} / \mathrm{kg})^{2}$ \\
Autocorrelation range & $900 \mathrm{~m}$
\end{tabular}

particular realizations present the measure of uncertainty of the prediction conducted by the simulation on the basis of the available observations. In the paper 50 independent realizations of the calorific value for the selected part of the deposit are presented. Figure 4 shows two exemplifying realizations.

Both of the used methods require a variogram model capturing the spatial variability as input. First an empirical variogram is calculated and secondly a model is fitted. In the presented case the spherical basic structure resulted in the best fit (Figure 3, Table 1). Due to the lack of a clear directional variability in the modelled deposit, an omnidirectional variogram model was used.

\section{The Data Base Used for the Analysis}

The variability models of calorific value were created based on 68 operational exploration drill holes located within the borders of mining and on the basis of the adjacent holes. Table 2 summarizes the basic statistical characteristics of the measurement data from 68 holes. As can be seen, both models perform well in reproducing the mean value of the drill holes. The variance of modelled blocks cannot directly be compared to the variance of exploration data, since both are based on a different support. However, it can be noticed that simulated block values appear more variable as Kriged block values. This effect results from the smoothing effect of Kriging. 

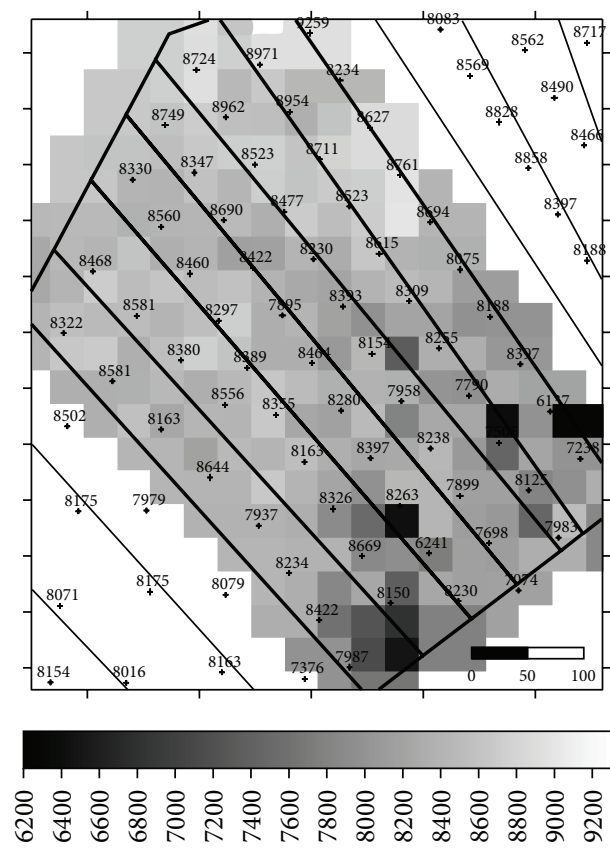

(a)

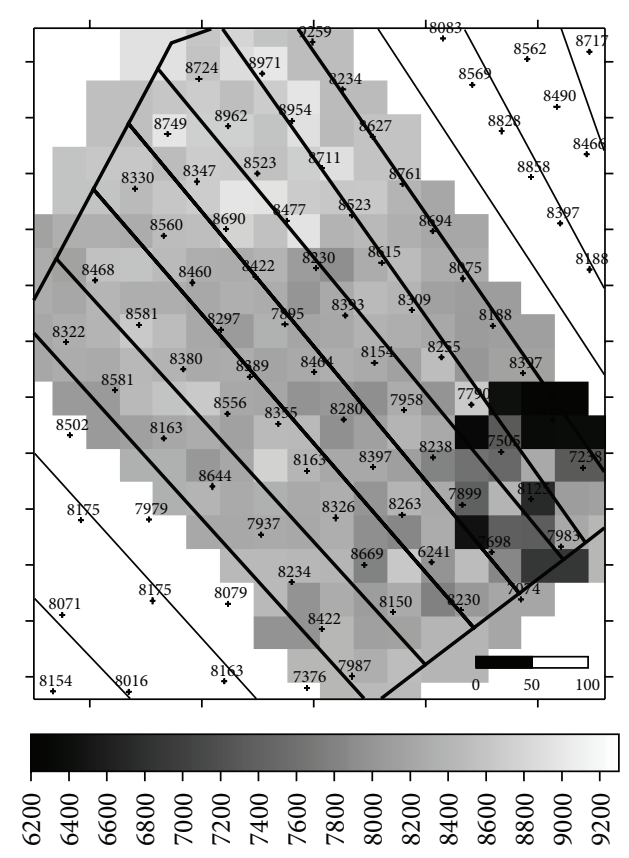

(b)

FIGURE 4: Models of calorific value $Q_{i}^{r}$-exemplifying realizations of geostatistical simulation.

TABLE 2: Basic statistics of calorific value based on 68 boreholes of the operational exploration and of the both models.

\begin{tabular}{|c|c|c|c|}
\hline & Data from the exploratory holes & Model ordinary Kriging & Model-exemplifying simulation \\
\hline Number of holes/number of blocks & 68 & $195(30 \times 30 \mathrm{~m})$ & $195(30 \times 30 \mathrm{~m})$ \\
\hline The mean value & $8267 \mathrm{~kJ} / \mathrm{kg}$ & $8274 \mathrm{~kJ} / \mathrm{kg}$ & $8260 \mathrm{~kJ} / \mathrm{kg}$ \\
\hline The standard deviation & $521 \mathrm{~kJ} / \mathrm{kg}$ & $316 \mathrm{~kJ} / \mathrm{kg}$ & $485 \mathrm{~kJ} / \mathrm{kg}$ \\
\hline Coefficient of variation & $6,30 \%$ & $3,80 \%$ & $5,9 \%$ \\
\hline The minimum value & $6137 \mathrm{~kJ} / \mathrm{kg}$ & $7517 \mathrm{~kJ} / \mathrm{kg}$ & $6225 \mathrm{~kJ} / \mathrm{kg}$ \\
\hline The maximum value & $9259 \mathrm{~kJ} / \mathrm{kg}$ & $8759 \mathrm{~kJ} / \mathrm{kg}$ & $9006 \mathrm{~kJ} / \mathrm{kg}$ \\
\hline
\end{tabular}

\section{Results and Discussion}

Figures 4 and 5 show the calorific value volatility models in the selected part of the deposit. To facilitate the assessment of the validity of the models, the figures also present the location of the operational exploration holes with their identified calorific value. Figure 4 shows two examples out of the total 50 conducted realizations of the simulation. The models differ from each other, and the differences are primarily in the blocks where there are no exploratory drill holes.

Figure 5 summarizes the two models representing the expected spatial distribution of the calorific value - the average of the 50 realizations (a) and using the ordinary Kriging method (b). In the model created using the Kriging the calorific value changes gradually. The contour lines shown in Figure 5(b) show the effect of smoothing that occurred when using ordinary Kriging. Contrarily the variability is conserved in the single realization (Figure 4 ). When averaging all realizations, resulting in the so-called E-type estimator
(Figure 5(a)), a very similar model to the one of Kriging is obtained.

Figure 6 presents the histograms of the calorific value models variability in the selected part of the deposit. There is an apparent narrowing of values in the ordinary Kriging model. Note that the Kriging smoothing effect can be compensated by implementing the Yamamoto correction.

Figure 7(a) shows the standard deviation of ordinary Kriging, which expresses the magnitude of the expected interpolation error. Its size in any given block depends primarily on the distance to the nearest observation, on the basis of which the interpolation was conducted. This relation results mainly from the variogram and the data configuration.

Kriging's standard deviation is independent of local variation of observations used for modelling. Figure 7(b) presents the map of the conditional simulation's standard deviation. The map is a result of a statistical analysis of 50 realizations. In each node of the grid standard deviation was calculated, reflecting the uncertainty of a local forecast. 

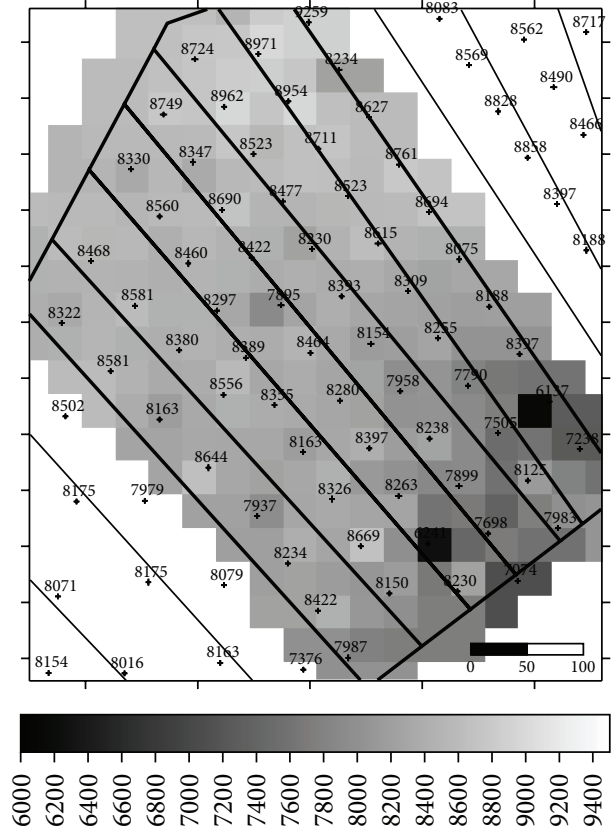

(a)

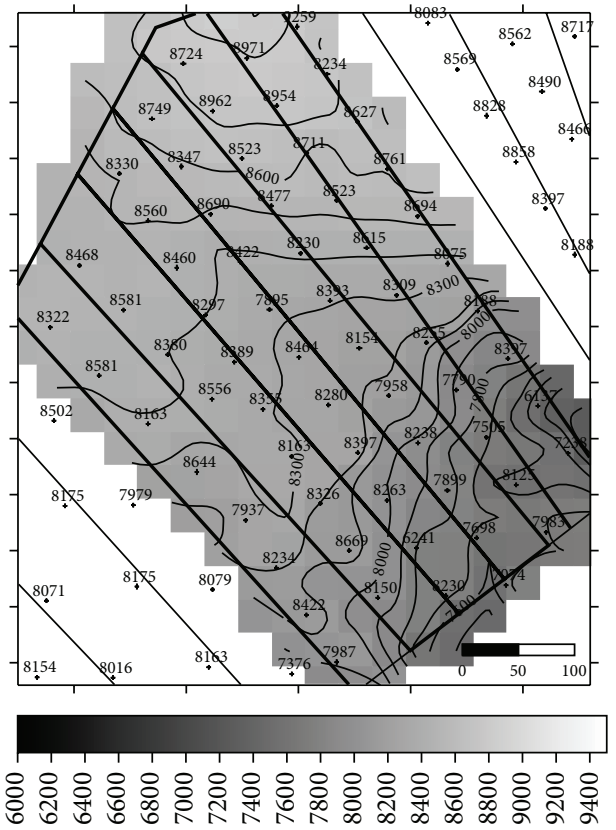

(b)

FIGURE 5: Variation of the calorific value $Q_{i}^{r}$-average of 50 realizations of the simulation (l) and ordinary Kriging (r).
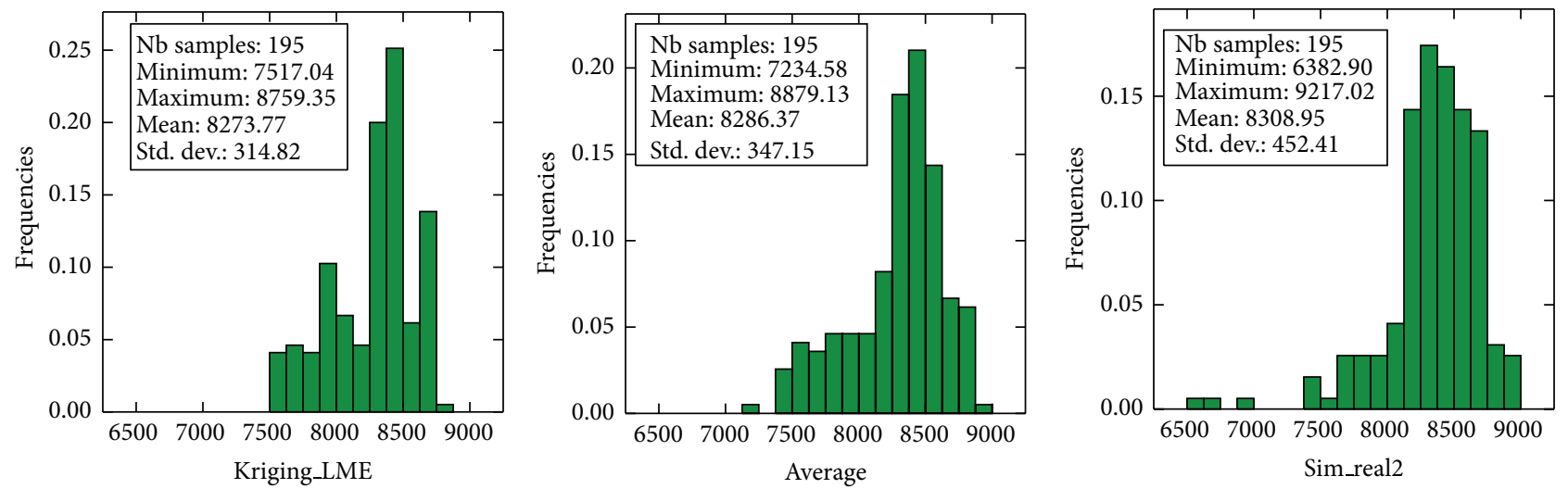

FiguRE 6: Histograms of calorific value $Q_{i}^{r}$ based on ordinary Kriging model (l), average of 50 realizations of a geostatistical simulation (m), and one realization of a geostatistical simulation (r).

There are some clear differences between the two figures. These differences appear not only in the nominal value of the standard deviation, but also in their spatial distribution in the modelled deposit. The standard deviation of the simulation shows particularly high values in the south-eastern part of the deposit. This is the influence of high calorific value variation of the adjacent observations.

Based on the assumed extraction schedule (Figure 2), graphs of the calorific value in the subsequently mined blocks (corresponding to the average daily production volumes) were prepared. Figures 8 and 9 depict the variations of the calorific value in the lignite stream during six months of mining. The graph in Figure 8 was created using the variability model prepared with the use of the ordinary Kriging method. Besides the mean value, the dotted lines constitute for the Kriging's standard deviation of the respective exploitation blocks. The graph in Figure 9 shows the variation of the calorific value based on the model created by conditional simulation method. Three exemplifying realizations of the simulation are shown together with the mean of all 50 realizations. Graphs (Figures 8 and 9 ) are supplemented with horizontal lines corresponding to the average value calculated from 68 observations $\left(Q_{s r}=8267 \mathrm{~kJ} / \mathrm{kg}\right)$ and the lines corresponding to the average increased $\left(Q_{g}=8788 \mathrm{~kJ} / \mathrm{kg}\right)$ and the average decreased by the value of the standard deviation of the observation $\left(Q_{d}=7746 \mathrm{~kJ} / \mathrm{kg}\right)$.

In the first graph (Figure 8), the average calorific value determined using Kriging changes cyclically within the range of the standard deviation of observation, extending only slightly beyond those lines. In the second graph (Figure 9) 

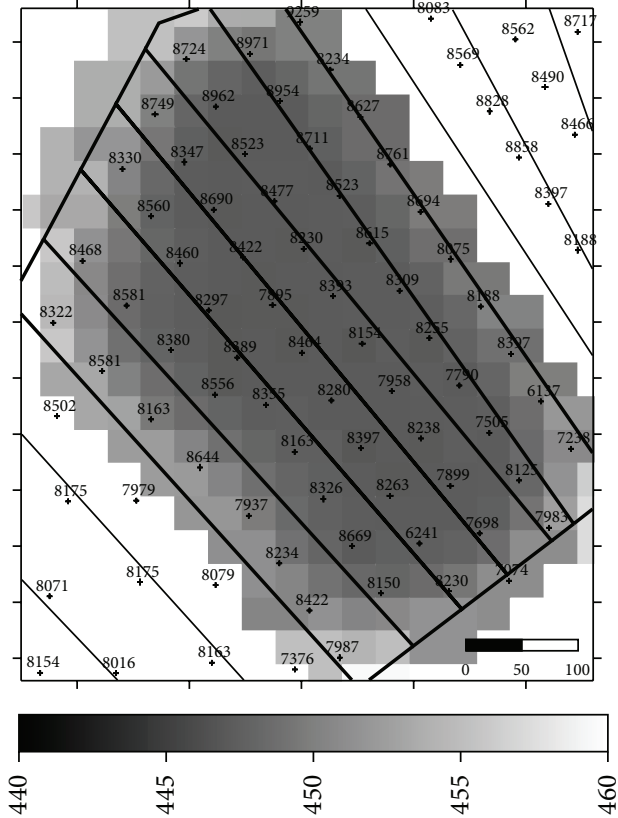

(a)

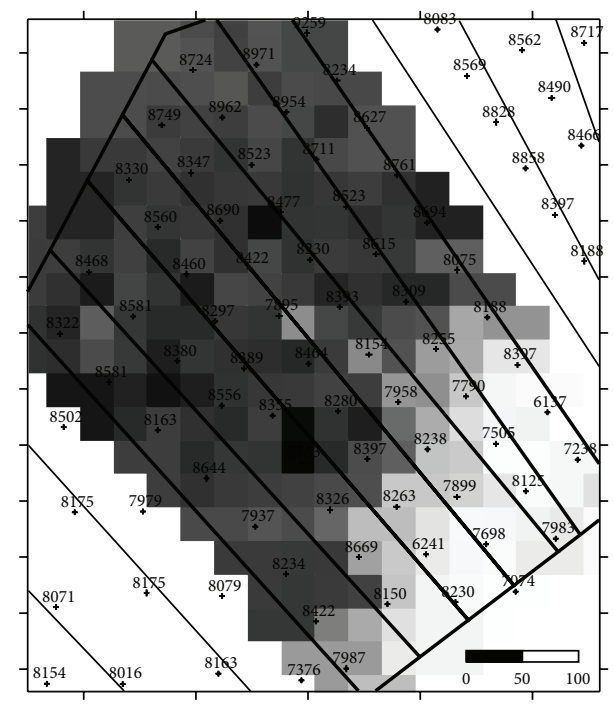

은 인

(b)

Figure 7: Standard deviation of Kriging (l) and standard deviation of simulation based on 50 realizations (r).

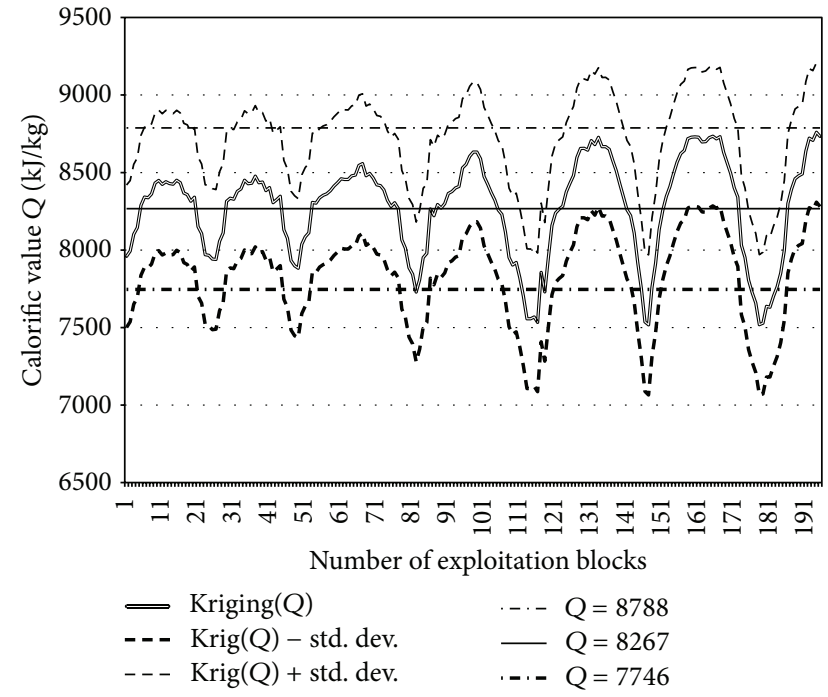

FIGURE 8: The fluctuation of calorific value $Q_{i}^{r}$ within 195 days of exploitation-based on ordinary Kriging.

the volatility of individual realization $(R 1, R 2$, and $R 3)$ is significant, and the mean of realizations (average $R 1, R 1, \ldots$, R50) in several places goes far beyond the limits of the line marking $Q_{d}=7746 \mathrm{~kJ} / \mathrm{kg}$, reaching a value below $Q=$ $6500 \mathrm{~kJ} / \mathrm{kg}$.

Based on the results of the 50 realizations of simulation, a map showing the probability of exceeding the thresholds established in the particular exploitation blocks was created. The values of the mean of 68 observations plus and minus the standard deviation were chosen as the assumed

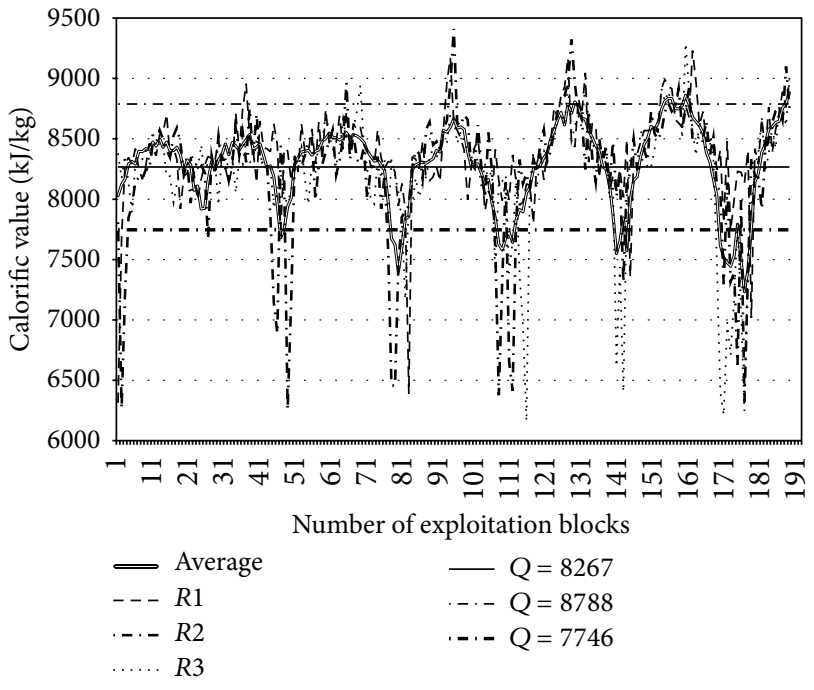

FIGURE 9: The fluctuation of calorific value $Q_{i}^{r}$ within 195 days of exploitation-based on conditional simulation.

limits (thresholds), which is rounded, respectively, to $Q_{g}=$ $8790 \mathrm{~kJ} / \mathrm{kg}$ and $Q_{d}=7750 \mathrm{~kJ} / \mathrm{kg}$. Figure 10 shows the map of the probability of exceeding the adopted thresholds.

\section{Investigation of Design Options}

Option 1 (bed blending using a coal-stock-and-blending yard). Bed blending has three objectives: namely, buffering, composing, and homogenising. Thereby it transforms the characteristics of the incoming material flow in an outgoing 


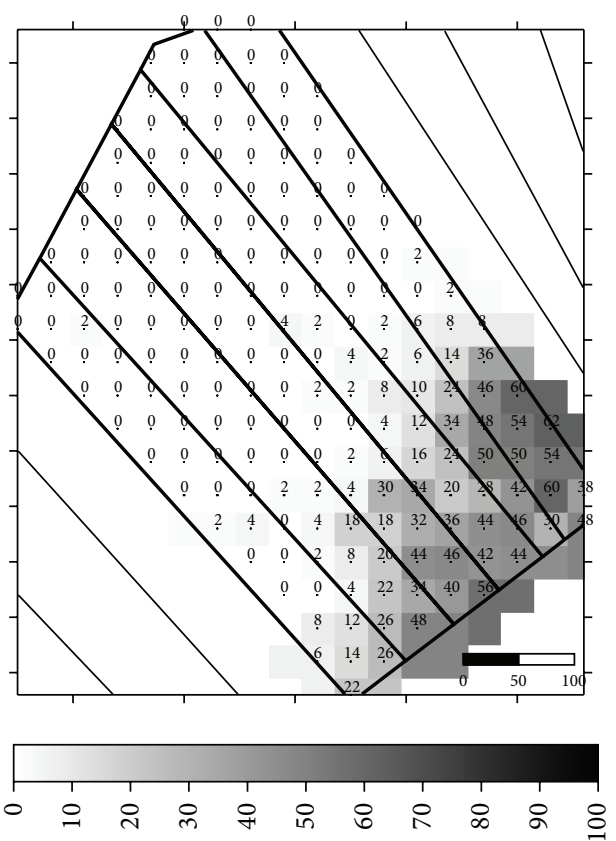

(a)

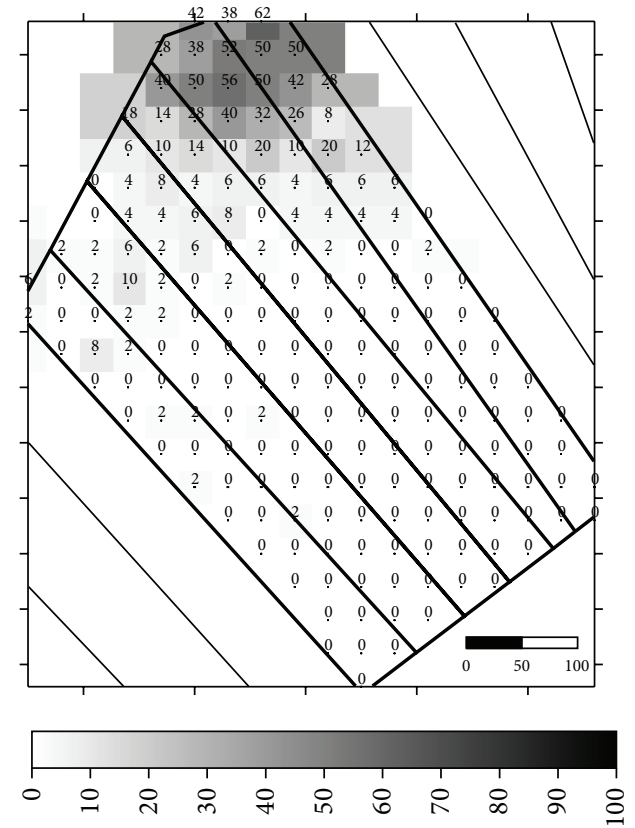

(b)

FIGURE 10: The occurrence probability of calorific value lower than $Q_{d}=7750 \mathrm{~kJ} / \mathrm{kg}(\mathrm{l})$ and higher than $Q_{g}=8790 \mathrm{~kJ} / \mathrm{kg}(\mathrm{r})$ in the exploitation blocks, based on simulation.

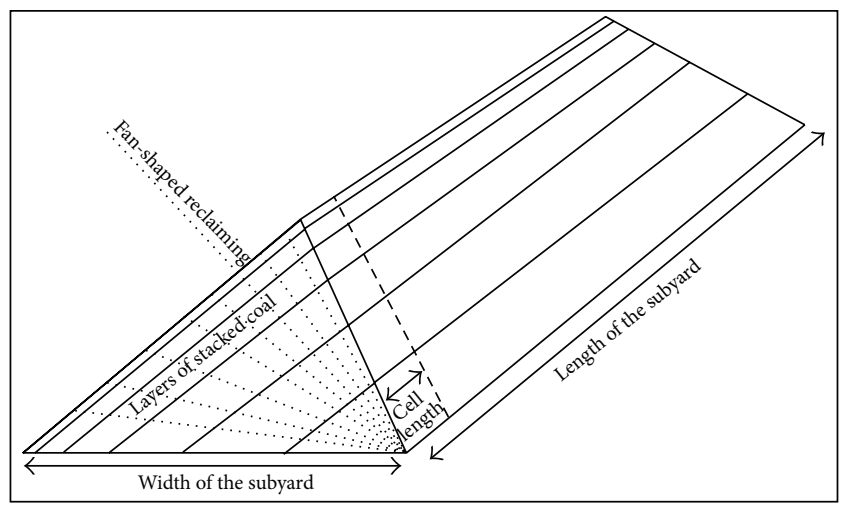

FIGURE 11: Schematic illustration of a strata-type blending yard.

material flow, whose characteristics are defined by costumer specifications and may be of contractual relevance. The characteristics of the incoming material flow are a function of the geological conditions, the applied selectivity in extracting the deposit, the mining sequence, and the operation mode in the pit as discussed in the previous section. The following considerations concern the homogenisation effect of using bed blending. The efficiency of blending and smoothing variability is significantly dependent on constructive parameters as well as the operation of the blending yard. Constructive factors are the type of the yard, its length and width, the angle of repose, the number of layers, and speed of the stacker. The following constructive parameters are given in the case study: the blending yard is of type "strata" (Figure 11).
The coal coming from the pit (incoming material flow) is stacked into layers, which are spread along the total length of a bed by a continuously up and down moving stacker. The number and thickness of the several layers are variable and can be influenced by the moving rate of the stacker dependent on the total production rate of the mine. At maximum about 61 layers can be placed in a pocket. The yard is reclaimed in a fan-shaped manner orthogonally to the alignment of the stacked layers by a scraper. In this way the coal quality of the outgoing material flow is formed as an average over the total number of stacked layers.

Investigations have shown that operating with $>15$ layers the incoming flow can be completely homogenized [5, 12]. Therefore in this investigation it is assumed that the homogenisation effect is solely dependent on the stockpile size. Figure 12 shows the variability of the outgoing material flow for the different blending yard sizes: $0 \mathrm{kt}, 60 \mathrm{kt}, 180 \mathrm{kt}$, and $300 \mathrm{kt}$. Clearly already a considerable small blending bed size leads to a significant homogenization. Considering the already previously introduced lower and upper limit of $Q_{g}=$ $8790 \mathrm{~kJ} / \mathrm{kg}$ and $Q_{d}=7750 \mathrm{~kJ} / \mathrm{kg}$ it would need a stockpile size of $>300$ kt to ensure continuously in-spec delivery of the power plant.

Figure 13 shows a summary of the frequencies of expected deviations from production targets for different blending bed sizes. For example a size of $180 \mathrm{kt}$ would still lead to approximately $5 \%$ of daily deliveries deviating from potentially contractually fixed limits. A size of $330 \mathrm{kt}$ would ensure that the in situ variability of the deposit can be transformed into a product exhibiting a maximum variability as requested from the customer. In addition this size of a stock pile would 


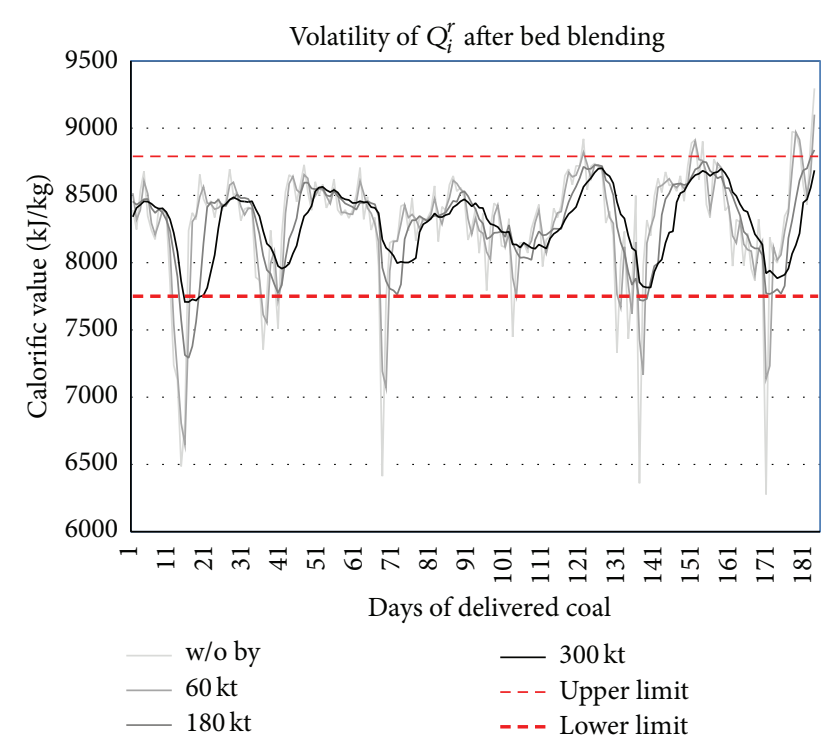

FIgURE 12: The fluctuation of calorific value $Q_{i}^{r}$ within 195 days of exploitation-after bed blending.

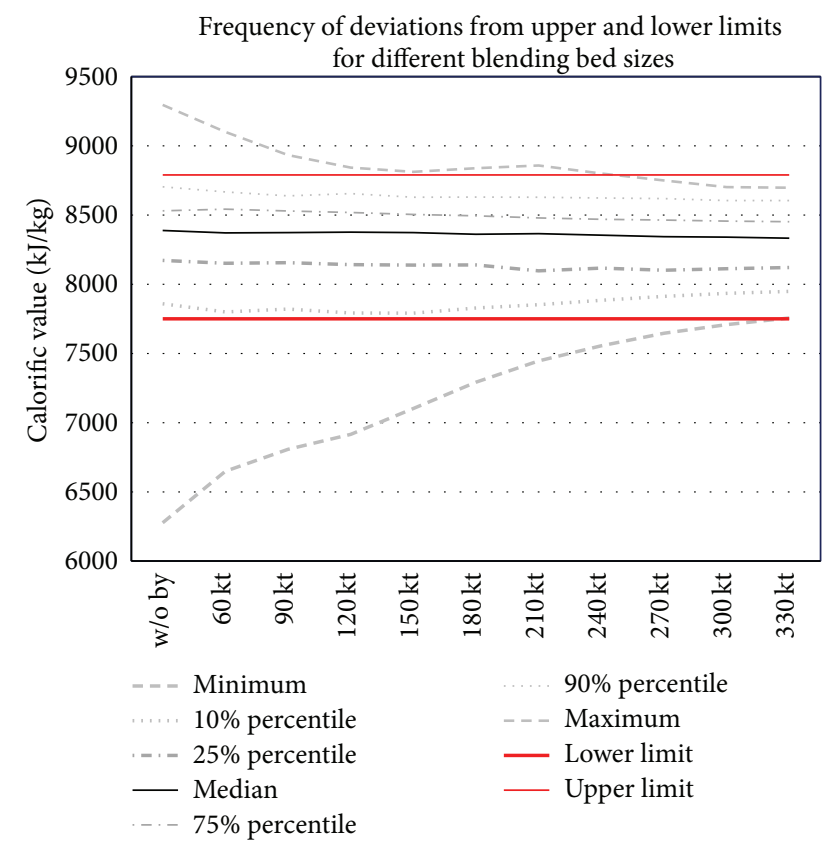

FIGURE 13: Distribution of calorific value as a function of blending yard sizes.

form a buffer bridging about 11 days of production and can ensure continuous supply of the power plant during small and medium termed maintenance or breakdown events.

Option 2 (availability of two excavators). This design option considers the availability of two excavators, which are operated simultaneously. For example excavator one may excavate the first part of the bench to the middle and excavator two extracts the remaining blocks. To avoid installed overcapacity the capacity of each of the two excavators can

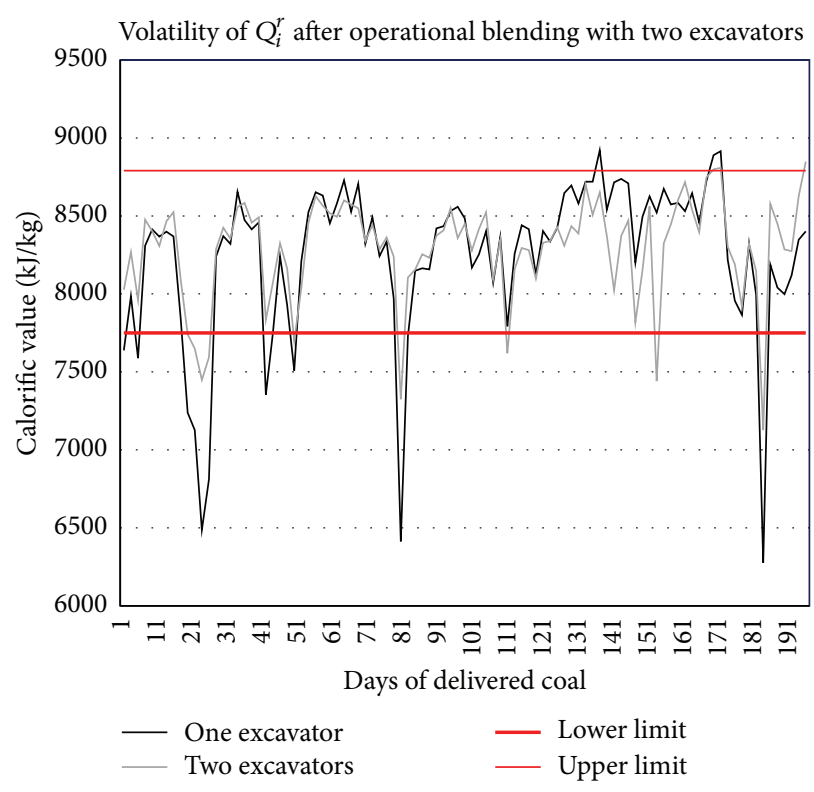

FIgURE 14: The fluctuation of calorific value $Q_{i}^{r}$ within 195 days of exploitation-using two excavators simultaneously.

be designed as low as half of the capacity of on single excavator achieving the same daily production target of $30 \mathrm{kt}$. For this investigation it was assumed that both excavators operate at an extraction rate of $15 \mathrm{kt}$ per day. Assuming no targeted quality optimized scheduling, which means both excavators are always operating at one half of the bench without pinpointed schedule, Figure 14 shows the result of the blended stream of lignite. As can be seen, a simultaneous extraction of blocks with a subsequent blending on the belt conveyor significantly reduces the variability. Considering the coal quality production limits it becomes obvious that there may still occur sporadic deviations from production targets. These can be avoided by quality optimized scheduling or using an additional blending yard with a small capacity, for example, $60 \mathrm{kt}$.

\section{Conclusions}

The calorific value of the analysed part of the deposit has a relatively low volatility $(6,3 \%)$, yet due to the elongated shape of the deposit (Figure 1), which implies the direction of mining and distribution of the calorific value, the average daily calorific values are in the range of $7750-8790 \mathrm{~kJ} / \mathrm{kg}$.

With the accepted method of mining, changes occur in almost regular monthly cycles. In two parts of the deposit the lignite has wider-than-threshold values (Figure 10). This applies mainly to the values lower than $7750 \mathrm{~kJ} / \mathrm{kg}$ in the south-eastern area, as well as more than $8790 \mathrm{~kJ} / \mathrm{kg}$ in the northern part of the deposit. For purposes of coal quality control in order to maintain the calorific value at the desired level, it is useful to apply modern spatial interpolation tools. The study shows that for this purpose geostatistical simulation is particularly useful as it-in addition to the mean valuesallows determining the level of the probability of exceeding 
the adopted thresholds in the particular blocks (risk level). In contrast to the simulation, using the ordinary Kriging interpolation may lead to erroneous operating decisions because of the effect of smoothing of the extreme values demonstrated in the paper.

The property of geostatistical simulation to reproduce in situ variability can be used to investigate the variability in dependence of certain design options in the subsequent material handling system. In the present case the availability and size of blending beds were investigated as well as the availability of an additional excavator. It has been shown that both options can contribute significantly to the reduction of variability in $C V$. In addition a required stock-pile size could be defined that ensures a continuous in-spec delivery of coal to the customer.

\section{Conflict of Interests}

The authors declare that there is no conflict of interests regarding the publication of this paper.

\section{References}

[1] W. Naworyta and S. Sypniowski, "About the problem of lignite stream quality control in the context of proper identification of deposit's quality parameters," Surface Mining, no. 2, pp. 58-65, 2013 (Polish).

[2] P. M. Gy, "A new theory of bed-blending derived from the theory of sampling-development and full-scale experimental check," International Journal of Mineral Processing, vol. 8, no. 3, pp. 201-238, 1981.

[3] M. Kumral, "Bed blending design incorporating multiple regression modelling and genetic algorithms," The Journal of the Southern African Institute of Mining and Metallurgy, vol. 106, no. 3, pp. 229-236, 2006.

[4] D. Marques, J. F. Costa, D. Ribeiro, and J. C. Koppe, "The evidence of volume variance relationship in blending and homogenisation piles using stochastic simulation," in Proceedings of the 4th World Forum on Sampling and Blending, pp. 235242, The Southern African Institute of Mining and Metallurgy, 2009.

[5] J. Benndorf, "Investigating the variability of key coal quality parameters in continuous mining operations when using stockpiles," in Advances in Orebody Modelling and Strategic Mine Planning I, AusIMM, 2011.

[6] J. Benndorf, "Investigating in situ variability and homogenisation of key quality parameters in continuous mining operations," Transactions of the Institutions of Mining and Metallurgy, Section A: Mining Technology, vol. 122, no. 2, pp. 78-85, 2013.

[7] D. Gärtner and R. Hempel, Monitoring and Control of Processes in the Lignite Mines in Rhineland, Lignite Mining, Springer, Heidelberg, Germany, 2009.

[8] L. Kunde and D. Trummer, "Coal quality management, lignite mining-Kohlenqualitätsmanagement (germ.)," in Der Braunkohlentagebau, pp. 409-426, Springer, Berlin, Germany, 2009.

[9] B. Zimmer, "Development of a new on-line coal quality management system in a lignite mine in Serbia," in Continuous Surface Mining, Latest Development in Mine Planning, Equipment and Environmental Protection: Proceedings of 10th International Symposium Continuous Surface Mining,
13-15 September 2010, C. Drebenstedt, Ed., pp. 290-302, Technische Universitat Bergakademie Freiberg, Freiberg, Germany, 2010.

[10] W. Naworyta, "Variability analysis of lignite deposit parameters for output quality control," Mineral Resources Management, vol. 24, no. 2-4, pp. 97-110, 2008 (Polish).

[11] W. Naworyta and J. Benndorf, "Accuracy assessment of geostatisticalmodelling methods of mineral deposits for the purpose of their future exploitation-based on one lignite deposit," Mineral Resources Management, vol. 28, no. 1, pp. 77-101, 2012 (Polish).

[12] J. Benndorf, "Application of efficient methods of conditional simulation for optimising coal blending strategies in large continuous open pit mining operations," International Journal of Coal Geology, vol. 112, pp. 141-153, 2013.

[13] N. Remy, A. Boucher, and J. Wu, Applied Geostatistics with SGeMS, Cambridge University Press, Cambridge, UK, 2009. 

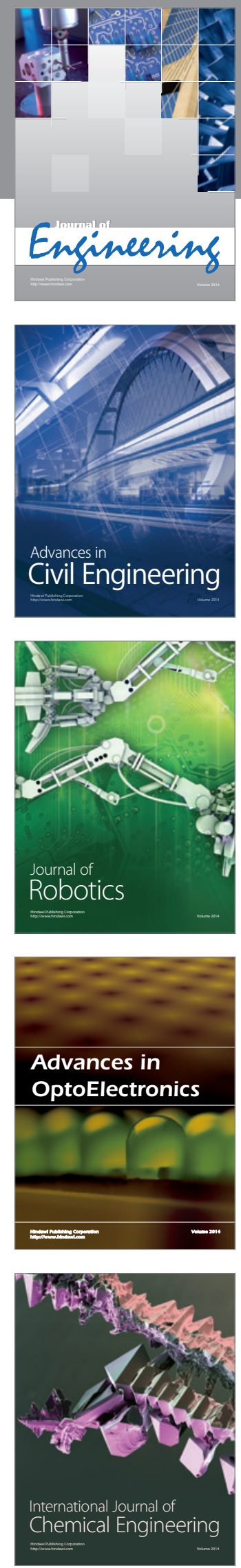

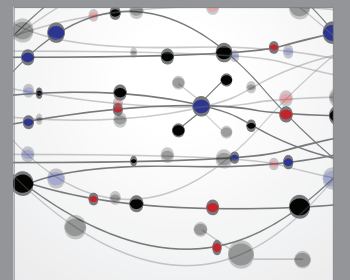

The Scientific World Journal
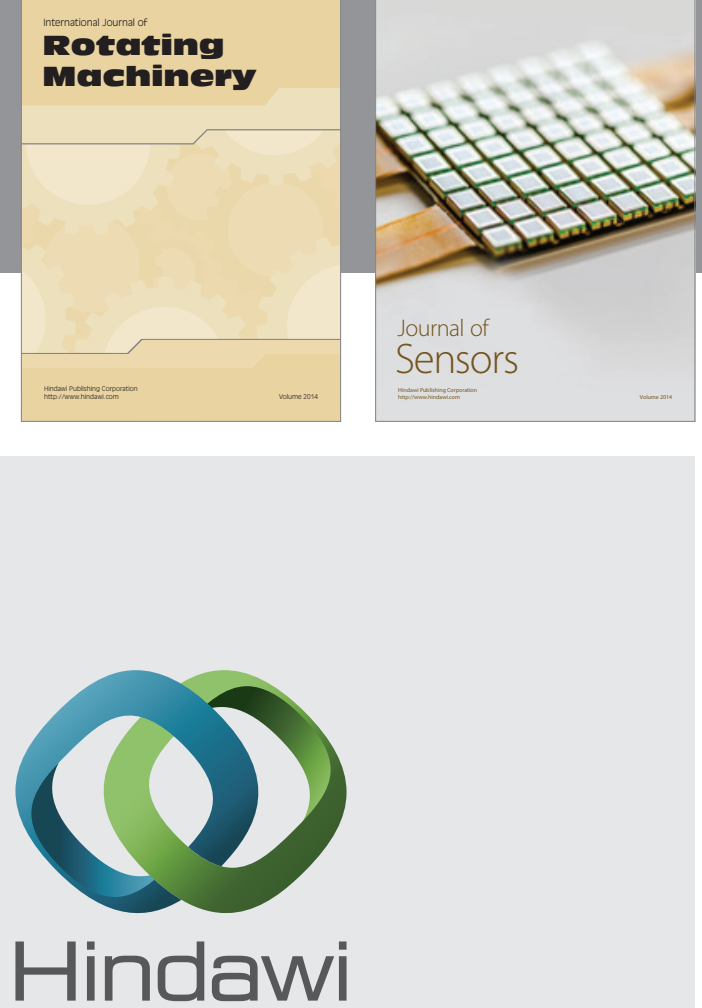

Submit your manuscripts at http://www.hindawi.com
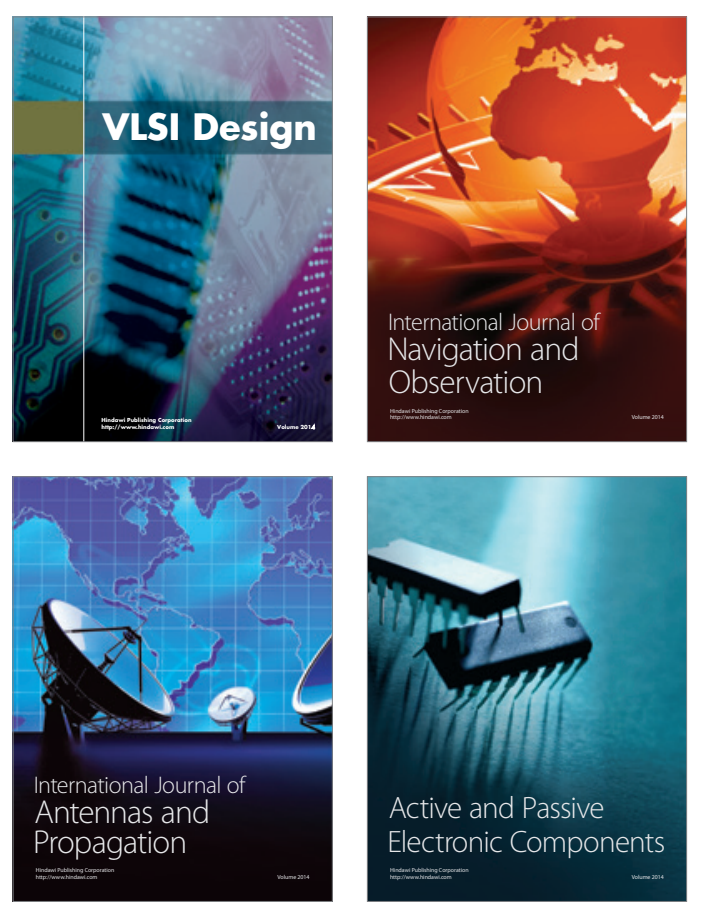
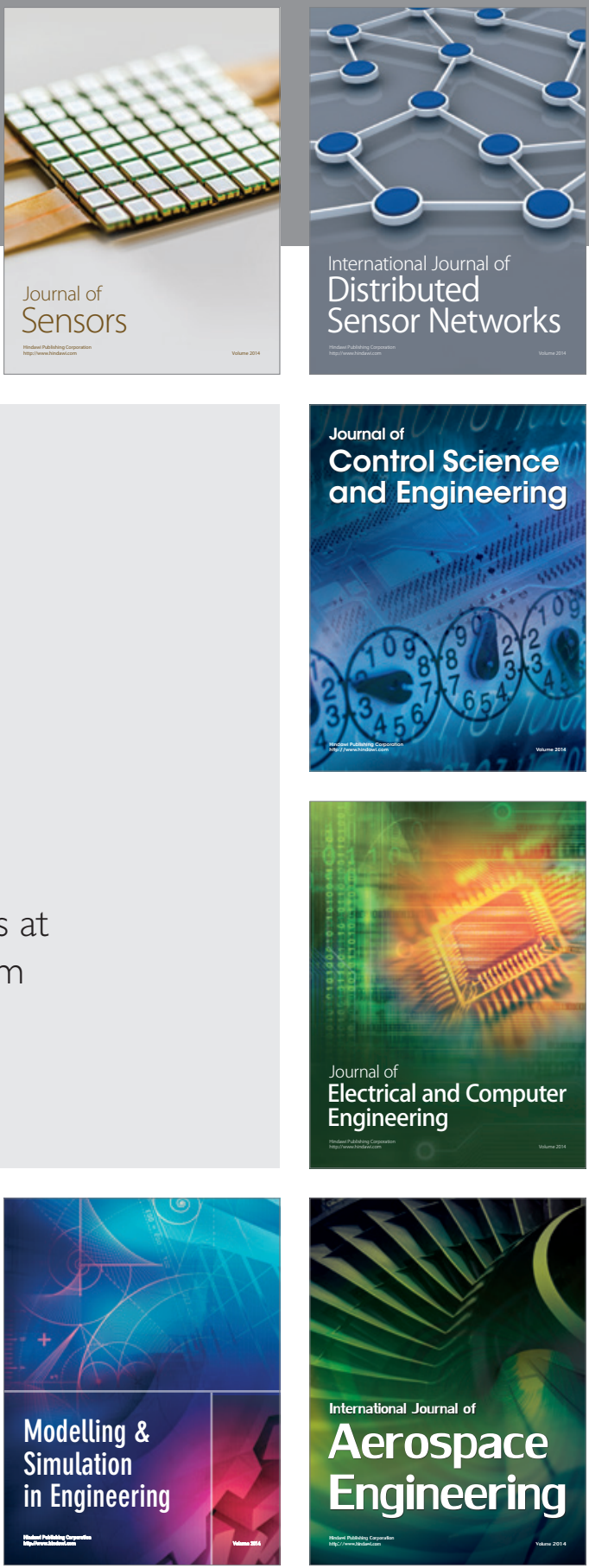

Journal of

Control Science

and Engineering
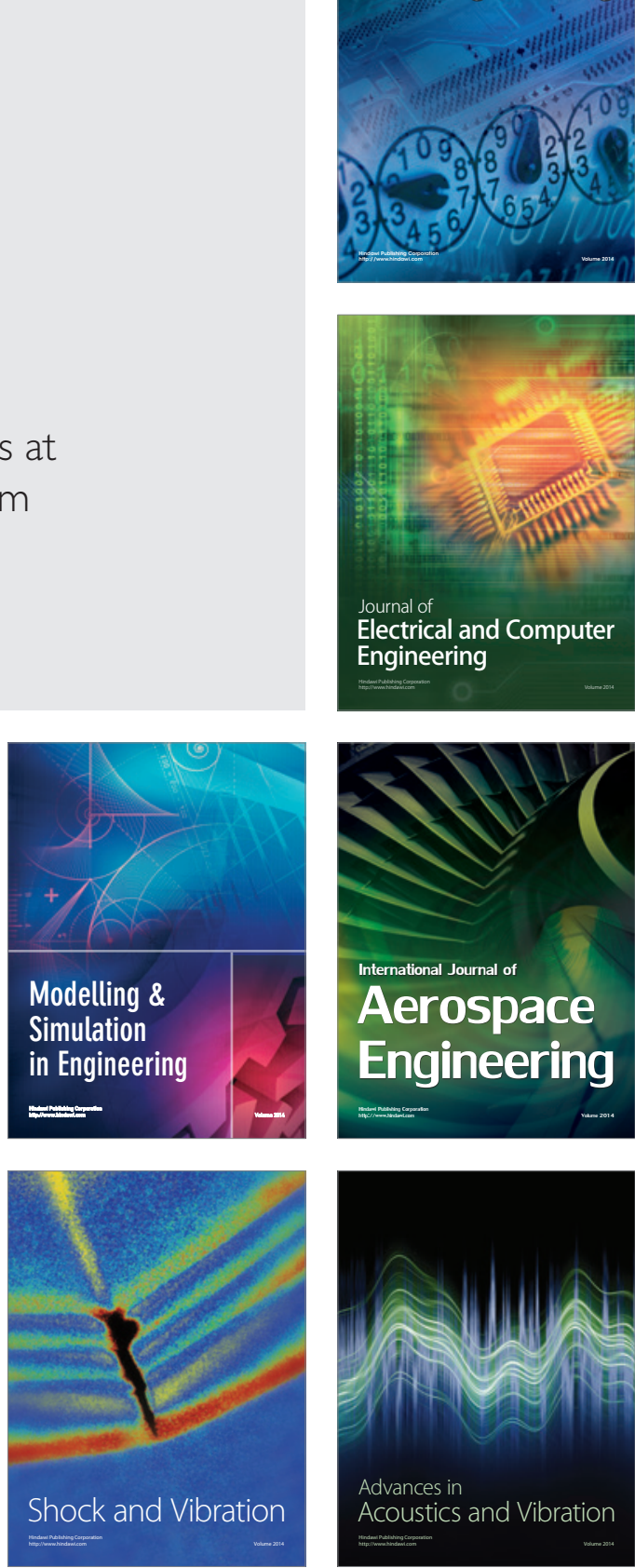